\title{
Blast Exposure Impairs Sensory Gating: Evidence from Measures of Acoustic Startle and Auditory Event-Related Potentials
}

\author{
Melissa A. Papesh,1,2 Jonathan E. Elliott,1,3 Megan L. Callahan,,4 Daniel Storzbach,1,3,4 \\ Miranda M. Lim, ${ }^{1,3,5,6}$ and Frederick J. Gallun ${ }^{1,2}$
}

\begin{abstract}
Many military service members and veterans who have been exposed to high-intensity blast waves experience traumatic brain injury (TBI), resulting in chronic auditory deficits despite normal hearing sensitivity. The current study sought to examine the neurological cause of this chronic dysfunction by testing the hypothesis that blast exposure leads to impaired filtering of sensory information at brainstem and early cortical levels. Groups of blast-exposed and non-blast-exposed participants completed selfreport measures of auditory and neurobehavioral status, auditory perceptual tasks involving degraded and competing speech stimuli, and physiological measures of sensory gating, including pre-pulse inhibition and habituation of the acoustic startle reflex and electrophysiological assessment of a paired-click sensory gating paradigm. Blast-exposed participants showed significantly reduced habituation to acoustic startle stimuli and impaired filtering of redundant sensory information at the level the auditory cortex. Multiple linear regression analyses revealed that poorer sensory gating at the cortical level was primarily influenced by a diagnosis of TBI, whereas reduced habituation was primarily influenced by a diagnosis of post-traumatic stress disorder. A statistical model was created including cortical sensory gating and habituation to acoustic startle, which strongly predicted performance on a degraded speech task. These results support the hypothesis that blast exposure impairs central auditory processing via impairment of neural mechanisms underlying habituation and sensory gating.
\end{abstract}

Keywords: electrophysiology; hearing; post-traumatic stress; TBI; veteran

\section{Introduction}

$\mathbf{T}$ He Department of Defense reports that between the years 2000 and 2017, nearly 380,000 military service members have been diagnosed with a traumatic brain injury (TBI), with $>312,000$ of these classified as mild (mTBI). ${ }^{1}$ The majority of these cases stemmed from exposure to high-intensity blast discharges, with incidence of blast exposure among military service personnel reaching levels as high as $8.3 \%$ in recent conflicts. ${ }^{2}$ Of those with deployment-related TBI, cognitive and sensory impairments are among the most prevalent symptoms reported, ${ }^{3,4}$ and these often persist for months or years following trauma. ${ }^{5-8}$

Among the most common sensory impairments reported following TBI are auditory complaints. Studies indicate that between $58 \%$ and $87 \%$ of veterans with mTBI stemming from blast exposure report auditory difficulties. ${ }^{9-11}$ The most common auditory complaints among these veterans include increased sensitivity to noise, poor speech understanding in the setting of competing background noise, difficulty understanding rapid speech, problems understanding speech on the telephone, difficulty following conversations among groups of people, poor recall of auditory infor-

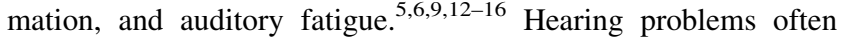
persist in spite of normal pure-tone hearing sensitivity, suggesting a central rather than peripheral locus of dysfunction. This assumption is corroborated by recent work showing that between $20 \%$ and $40 \%$ of veterans exposed to high-intensity blasts demonstrate abnormal performance on behavioral and electrophysiological assessments of the central auditory system. ${ }^{17,18}$ Similar patterns of auditory deficits have been reported in blast-exposed veterans even after several years of recovery after blast exposure. ${ }^{6}$

One potential mechanism by which blast exposure affects auditory processing could be impairment of "sensory gating," or the

\footnotetext{
${ }^{1}$ National Center for Rehabilitative Auditory Research, VA Portland Health Care System, Portland, Oregon.

Departments of ${ }^{2}$ Otolaryngology Head and Neck Surgery, ${ }^{3}$ Neurology, and ${ }^{4}$ Psychiatry, ${ }^{5}$ Department of Medicine, Division of Pulmonary and Critical Care Medicine, and ${ }^{6}$ Department of Behavioral Neuroscience and Oregon Institute of Occupational Health Sciences, Oregon Health \& Science University, Portland, Oregon.

(C) Melissa A. Papesh et al., 2018; Published by Mary Ann Liebert, Inc. This Open Access article is distributed under the terms of the Creative Commons License (http://creativecommons.org/licenses/by/4.0), which permits unrestricted use, distribution, and reproduction in any medium, provided the original work is properly credited.
} 
process by which sensory information is filtered for relevant content prior to being processed by higher order cognitive regions. Sensory gating occurs at pre-attentive levels of stimulus processing and plays an important role in preventing interference by sensory stimuli during higher-order functions such as attention and memory. ${ }^{19,20}$ Reduced sensory gating, measured using a paired-click auditory evoked potentials (AERP) paradigm, was previously reported in a study of TBI patients with attention and memory dysfunction, ${ }^{21}$ providing support for a potential link between blast exposure and impaired sensory gating. Poor sensory gating could account for auditory-specific deficits in blast-exposed veterans such as difficulty understanding speech signals in the context of background noise and comprehension of rapidly spoken speech, as well as cognitive symptoms such as difficulty attending to and recalling long conversations and lists of spoken instructions.

Common methods of assessing sensory gating include: (1) measurement of habituation ${ }^{22,23}$ and pre-pulse inhibition (PPI) ${ }^{24}$ of the acoustic startle reflex (ASR), which primarily evaluates brainstem pathways; and (2) AERP elicited using a well-established pairedclick paradigm ${ }^{25-27}$ that primarily targets responses from thalamocortical and cortical pathways.

Therefore, in the current study, we aimed to explore the relationship between auditory perception (using self-report and behavioral testing) and sensory gating using both acoustic startle and AERP in veterans with previous exposure to high-intensity blast waves. We hypothesized that blast-exposed veterans would demonstrate reduced sensory gating and that poor auditory perception in blast-exposed veterans would be correlated with biological markers (i.e., habituation to ASR and AERP) of impaired sensory gating.

\section{Methods}

\section{Participants}

Twenty-nine combat-deployed veterans were recruited from the Veterans Affairs Portland Health Care System (VAPORHCS) in Portland, Oregon, including those who had been exposed to highintensity blast discharges within the past 10 years, as well as those with no history of blast exposure or brain injury. Potential participants completed an interview regarding their military service, prior head trauma, and blast exposure(s), including symptoms immediately and within the first $24 \mathrm{~h}$ of injury. Only participants who met basic criteria for brain injury (e.g., disorientation, ringing in the ears, nausea, light sensitivity, loss of consciousness, posttraumatic amnesia, and headache immediately following the event) established by the Defense and Veterans Brain Injury Center (DVBIC) were admitted to the blast-exposed participant group. All participant reports were consistent with a classification of mTBI. Although a medical chart review was also performed to determine if a clinical diagnosis of TBI had been made, blast-exposed participants without the clinical diagnosis of TBI were still included in the study, as previous work has indicated that patients who meet the DVBIC criteria for brain injury following blast exposure experience auditory dysfunction similarly to those who have received a blast-related diagnosis of TBI. ${ }^{6,17,18,28}$ Additional exclusionary criteria included pure-tone hearing thresholds $>30 \mathrm{~dB}$ hearing level (HL) at any test frequencies between 250 and $4000 \mathrm{~Hz}$, threshold differences of $>10 \mathrm{~dB}$ between the left and right ear at any test frequency, and diagnosis of mental health conditions associated with poor sensory gating including schizophrenia, bipolar disorder, obsessive compulsive disorder, and attention-deficit/hyperactivity disorder. Sixteen participants (all males) were admitted to the blast-exposed group (average age 36.9 years; age range 24-58 years), and 13 participants ( 2 females) were admitted to the control group (average age 38 years, age range $19-66$ years). The Institutional Review Board at the VAPORHCS approved this project, and all subjects provided oral and written informed consent prior to participation.

\section{Study overview}

Testing was completed over two to three visits (Fig. 1). Visit 1 consisted of screening measures, including an audiological assessment, an interview of past head traumas, and a medical history questionnaire. Once inclusionary criteria were confirmed, participants then completed speech-in-noise perception testing as well as additional self-report questionnaires. Following visit 1, a medical record review was conducted to determine if a diagnosis of posttraumatic stress disorder (PTSD) was present, and to confirm selfreported reported medical history. Visit 2 consisted of sensory gating testing, including both the ASR and AERP analyses. All participants completed visits 1 and 2 .

Visit 3, which was not part of the original study design, was added to further assess comprehension of competing and degraded speech. All participants were invited back for this third visit; $15 / 16$ blast-exposed participants, and 9/13 control participants returned for this test session.

\section{Self-report measures}

All participants completed a medical case history questionnaire including questions assessing audiological history, military service, other health diagnoses, and use of medications, cigarettes, alcohol, and illicit drugs. The Functional Hearing Questionnaire (FHQ), developed for veterans with brain injuries was used to evaluate selfperceived hearing difficulties. ${ }^{5}$ The FHQ is a nine item questionnaire that asks participants to rate their level of difficulty hearing in different circumstances on a four point scale. Scores range from 9 to 36 , with higher scores indicating a greater level of difficulty. The Hearing Handicap Inventory for Adults (HHIA) ${ }^{29}$ was used to assess the social and emotional impact of hearing difficulties on
Visit 1

\begin{tabular}{|l|}
\hline Screening: \\
Audiometry, TBI \\
Interview, \& Medical \\
History Questionnaire \\
Self-Report Measures: \\
FHQ, HHIA, \& NSI \\
Speech-in-Noise Perception: \\
AzBio (0 \& +5 dB SNR), \\
\& CNC \\
\hline
\end{tabular}

Visit 2

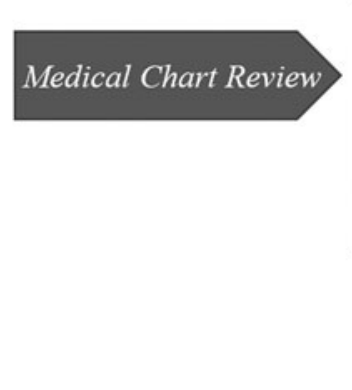

Visit 3

\begin{tabular}{l|l|}
$\begin{array}{l}\text { Auditory Event-related } \\
\text { Potentials }(A E R P): \\
\text { Cortical Sensory Gating } \\
\text { \& Acoustic Startle Reflex } \\
\text { (baseline, PPI, \& } \\
\text { habituation) }\end{array}$ & $\begin{array}{l}\text { Degraded and Dichotic } \\
\text { Listening: } \\
\text { DDT, SSW, \& CWT }\end{array}$ \\
\hline
\end{tabular}

FIG. 1. Schematic representation of study visits and procedures. 
everyday life. The HHIA is a 25 item questionnaire that asks patients to rank how often auditory issues create problems in daily life. Scores range from 0 to 100 , with higher scores indicating greater perceived levels of handicap. Lastly, all participants completed the Neurobehavioral Symptom Inventory- $22(\mathrm{NSI})^{30}$ to assess post-concussive symptom severity. Each item is scored from 0 , indicating no problem, to 4 , indicating a severe debilitating problem.

\section{Behavioral speech perception testing}

All speech testing was completed in a sound-attenuating chamber using ER3-A insert earphones (Etymotic Research, Elk Grove Village, IL). Speech-in-noise tests were selected from the Minimum Speech Test Battery ${ }^{31}$ and presented via a CD player routed through an audiometer. The AzBio was selected as a sentence-level speech perception test. This test is composed of target sentences spoken by two male and two female speakers using conversational speech patterns presented at a level of $60 \mathrm{~dB}$ HL. ${ }^{32}$ Conditions included binaural presentation of target sentences in quiet, and in the presence of 10-talker speech babble presented at $55 \mathrm{~dB}$ HL and $60 \mathrm{~dB}$ HL resulting in signal-to-noise ratios (SNR) of $+5 \mathrm{~dB}$ and $0 \mathrm{~dB}$ for the two speech-in-babble conditions, respectively. Each condition included 20 target sentences that participants were asked to repeat to the researcher. Word-level speech perception was measured using the Consonant-Nucleus-Consonant (CNC) test. ${ }^{33} \mathrm{CNC}$ test materials are comprised of monosyllabic words spoken by a female talker, each preceded by the carrier phrase "Ready". Each word consists of three speech phonemes including two consonant sounds with a vowel in the middle. CNC target words were presented at a level of $60 \mathrm{~dB} \mathrm{HL}$ in quiet and in $55 \mathrm{~dB}$ HL of background noise $(+5 \mathrm{~dB}$ SNR) with a spectrum matching the average long-term spectrum of speech. In each condition (quiet and noise), responses were scored based upon the number of phonemes correctly repeated with a maximum score of 150 for each condition. Results for both the AzBio and CNC tests are presented as percent correct for each condition.

Additional speech tests included in the third test session consisted of two tests of competing dichotic speech (the Dichotic Digits Test [DDT] and the Staggered Spondaic Words [SSW] test) and one test of degraded speech (the Compressed Word Test [CWT] test). Each of these tests were developed for the clinical assessment of central auditory processing disorders, and previous research has indicated that blast-exposed veterans often perform poorly on these measures. ${ }^{6,18}$ Tests were presented at a level of $35 \mathrm{~dB}$ above each participant's speech recognition threshold, determined during the audiological evaluation at the first visit, to ensure equivalent levels of audibility across all participants. The DDT consists of four numbers, two spoken to each ear nearly simultaneously. ${ }^{34}$ Participants were asked to repeat back all four numbers in any order, and scores were reported as percent correct. The SSW test consisted of 40 pairs of "spondaic" words, each "spondee" consisting of two complete one-syllable words (e.g., "cupcake") spoken with equal emphasis on both syllables. ${ }^{35}$ In each trial, the two spondees were presented, one to each ear, such that the first syllable of the first spondee was presented in quiet in one ear and the second syllable of the first spondee overlapped the first syllable of the second spondee in the opposite ear. Participants were asked to repeat back both words and scores were reported as the total number of errors out of all 80 words. Lastly, the CWT test consisted of 50 monosyllabic words time-compressed to $45 \%$ of their original duration. ${ }^{36}$ Each ear was tested separately and participants were asked to repeat back each word, with scoring reported as percentage of words correctly repeated.

\section{Measurement of PPI and habituation of the ASR}

The acoustic startle stimulus consisted of a $40 \mathrm{~ms}$ duration burst of white noise presented at a level of $113 \mathrm{~A}$-weighted decibels
(dBA) with a nearly instantaneous rise time. Stimuli were presented binaurally via ER3A insert earphones (Etymotic, Elk Grove Village, IL) over a continuous background of white noise presented at $60 \mathrm{~dB}$ A. All stimulus presentations and responses were recorded using the Neuroscan Synamps System II (NeuroScan Inc., El Paso, TX). The skin below the left eye and on the forehead was first exfoliated and then cleansed using an alcohol swab. Eye blink responses to startle stimuli were measured by recording the electromyographic (EMG) activity from the orbicularis oculi muscle under the left eye using two EL254 Ag-AgCl electrodes (BIOPAC Systems, Inc., Goleta, CA) spaced $\sim 25 \mathrm{~mm}$ apart. An additional ground electrode was placed on the forehead.

Participants were seated in a reclining armchair within a doublewalled sound-attenuating chamber and instructed to look at a static image of a beach scene located on the wall in front of them to maintain vigilance and eye gaze. Prior to testing, all participants were given the opportunity to listen to the acoustic startle stimulus to ensure tolerability. Testing began with the background white noise presented for $2 \mathrm{~min}$ to allow participants to acclimate to the sound and test environment. All stimuli were presented at an average inter-trial interval of $\sim 45 \mathrm{sec}$ (range $35-55 \mathrm{sec}$ ). Four startle stimuli were initially presented, and the average EMG magnitude in response to these four initial startle stimuli was taken as the baseline startle response. Participants were then presented with 16 additional startle stimuli, 8 of which were preceded by a low-amplitude pre-pulse tone presented $120 \mathrm{~ms}$ before the startle stimulus. The sequence of startle-only and prepulse and startle stimuli were randomized for each participant. The experiment ended with four additional startle stimuli (without pre-pulse tones), and the average EMG response to these final four stimuli was taken as the habituated startle response.

The raw EMG signal was amplified, sampled at $1000 \mathrm{~Hz}$, bandpass filtered between 30 and $200 \mathrm{~Hz}$, and rectified. Responses to startle stimuli were defined as EMG peak amplitude in a time window from 20 to $120 \mathrm{~ms}$ after stimulus presentation. Trials with excessive EMG artifact, which obscured the response stimulus, were excluded ( $\sim 3 \%$, or 12 of the 416 total trials). PPI was defined as the reduction in the magnitude of response from startle stimulusonly trials to prepulse and startle stimulus trials, and was calculated as the percent change in amplitude. Habituation was defined as the reduction in response magnitude from the initial four startle stimulus presentations to the final four startle stimulus presentations, and was calculated as the percent change in amplitude.

\section{Measurement of cortical sensory gating}

All participants were asked to abstain from consuming caffeine and smoking cigarettes for a minimum of $2 \mathrm{~h}$ prior to completing the cortical sensory gating protocol, to avoid excitation of nicotinic receptors, which can temporarily improve sensory gating. ${ }^{37,38}$ Participants were seated comfortably in a sound attenuating booth, and instructed to ignore the test stimuli and watch a silent closedcaptioned movie of their choice. A validated paired-click testing paradigm was used, ${ }^{25-27}$ to target thalamocortical and auditory cortex responses. On each trial, two identical $10 \mathrm{~ms}$ clicks were presented with an inter-stimulus interval of $500 \mathrm{~ms}$. The conditioning (first click) and test (second click) stimuli were presented binaurally at a level of $80 \mathrm{~dB} C$ via ER3A insert earphones. A total of 200 trials (consisting of both a conditioning and a test click) were presented. ERP responses were obtained using a 64 channel cap (Electro-Cap International, Inc.; Eaton, $\mathrm{OH}$ ) and the Compumedics Neuroscan System (Charlotte, NC). The ground electrode was located on the forehead, and $\mathrm{Cz}$ served as the reference electrode during recordings. Data were then re-referenced off line to an average reference of all electrodes. Horizontal and vertical eye movement was monitored with electrodes located inferiorly and at the outer canthi of both eyes. The recording time window consisted of a $200 \mathrm{~ms}$ pre-stimulus baseline following by an $1100 \mathrm{~ms}$ post-stimulus onset. Responses 
were analog low-pass filtered online at $100 \mathrm{~Hz}(12 \mathrm{~dB} /$ octave roll off), and all channels were amplified with a gain $\times 10$ and converted using an analog-to-digital sampling rate of $1000 \mathrm{~Hz}$. Trials with eye blink artifacts were corrected off line using Neuroscan software. This blink reduction procedure calculates the amount of covariation between each active recording channel and a vertical eye channel using a spatial, singular value decomposition, and removes the vertical blink activity from each electrode on a point-by-point basis to the degree that the evoked response and blink activity co-varied. After blink correction, trials containing artifacts $> \pm 70 \mu \mathrm{V}$ were rejected from averaging. For all individuals and conditions, $\geq 70 \%$ of the collected trials were available for averaging after artifact rejection. After artifact rejection, the remaining sweeps were averaged (an average of 178 sweeps per participant after artifact rejection and a minimum of 142 sweeps) and filtered off line.

The latencies and amplitudes of $\mathrm{P} 1, \mathrm{~N} 1$, and $\mathrm{P} 2$ peaks were obtained from the central electrode $\mathrm{Cz}$. For N1 and $\mathrm{P} 2$ peaks, offline bandpass filters from $0.1 \mathrm{~Hz}$ (high-pass filter, $24 \mathrm{~dB} /$ octave) to $30 \mathrm{~Hz}$ (low-pass filter, $12 \mathrm{~dB} /$ octave) were used to maximize cortical responses while reducing extraneous noise. P50 peaks were analyzed after applying a bandpass filter from 10 to $30 \mathrm{~Hz}$, because of the higher frequency content of thalamocortical responses. ${ }^{39}$ Peak values were confirmed by comparing peaks at the $\mathrm{Cz}$ electrode location with peaks in the inverted waveforms measured at temporal electrode locations, as well as comparison with global field power traces for each individual, and grand averaged subject group responses. Amplitude values were measured relative to pre-stimulus baseline. Gating was defined as the reduction in peak amplitude from the conditioning (S1) to the test stimulus (S2) of a stimulus pair, and calculated as percent change in response amplitude [(S1amplitudeS2amplitude/S1amplitude) $\times 100$ ]. The change in amplitude between responses to conditioning and test stimuli is hereafter referred to as $\Delta \mathrm{P} 1, \Delta \mathrm{N} 1$, and $\Delta \mathrm{P} 2$, to denote changes in each peak.

\section{Statistical analysis}

All statistical analysis was completed using SPSS. Group differences for all test measures were assessed via one way ANOVA with $\alpha$ set a priori to $p<0.05$. Bivariate correlations were conducted using Kendall's tau-b to assess relationships among selfreport, demographic, behavioral, and physiological test measures. Kendall's tau was used because it is independent of underlying distributions and because the resulting significance values are more accurate in small sample sizes than those of other non-parametric measures such as Spearman's rho. ${ }^{40,41}$ In light of the multiple comparisons necessary in the correlation analysis, we employed a Benjamani-Hochberg correction to limit the false discovery rate to $\leq 10 \%$. Last, stepwise multiple linear regression was used to determine which test variables were significant predictors of sensory gating indices and behavioral test performance.

\section{Results}

\section{Participant characteristics}

Audiometric thresholds were within the clinically normal range of hearing for both groups, specified as thresholds of $\leq 25 \mathrm{~dB}$ HL at test frequencies between 250 and $8000 \mathrm{~Hz}$. Blast-exposed participants had, on average, significantly more years of military experience, with an average of 11.6 years, compared with controls who had an average of 5.8 years $\left(F_{(1,27)}=4.367 ; p=0.046\right)$. Both groups had high rates of comorbid medical diagnoses, including sleep disorders, depression, anxiety, tinnitus, and migraines. Medical chart review indicated that $13 / 16$ blast-exposed and $5 / 13$ control participants had a diagnosis of PTSD $\left(F_{(1,27)}=20.343 ; p<0.001\right)$. Blast-exposed participants reported an average of 9.75 blast exposures or other types of brain injuries (range from 1 to 30) with an average of 7.1 blast exposures/participant (range from 1 to 30 ) and the most severe blast injury occurring an average of 7.4 years previous to participation in the study (range of 3-10 years). Eleven of the 16 blast-exposed participants had a medical chart confirmed diagnosis of TBI, all of which were classified as mild.

\section{Self-report measures}

The upper portion of Table 1 shows the group average and standard deviations of each self-report test measure as well as ANOVA results. Group differences were significant for all self-report measures, with blast-exposed participants endorsing higher perceived levels of auditory dysfunction and handicap on the FHQ and the HHIA, and greater severity of neurobehavioral post-concussive symptoms on the NSI compared to control group participants. Overall, group differences of perceived auditory function on the FHQ were driven by greater difficulty understanding on the telephone $\left(F_{(1,27)}=6.458\right.$; $p=0.017)$ and when speech was spoken rapidly $\left(F_{(1,27)}=5.649\right.$; $p=0.025)$ among the blast-exposed group. Difficulties with understanding in background noise $\left(F_{(1,27)}=3.817 ; p=0.061\right)$ and following long conversations $\left(F_{(1,27)}=4.180 ; p=0.051\right)$ were also endorsed at higher rates among blast-exposed veterans.

\section{Auditory perception measures}

Average performance of each participant group on all tests of auditory perception are shown in Figure 2A. Performance among the blast-exposed participants tended to be somewhat poorer than that of control participants; however, this difference was only significant for the CWT presented to the left ear (Table 1). Responses to right ear presentations of the CWT $(p=0.06)$ and responses to the SSW $(p=0.094)$ also demonstrated a trend toward significantly worse performance in the blast-exposed group. Based

Table 1. Group Averages, Standard Deviations, and Statistical Analysis for Each Self-Report and Behavioral Test Measure

\begin{tabular}{lllll} 
& & & \multicolumn{2}{c}{ ANOVA } \\
\cline { 4 - 5 } $\begin{array}{l}\text { Self-report } \\
\text { measures }\end{array}$ & $\begin{array}{c}\text { Blast-exposed } \\
\text { mean }(S D)\end{array}$ & $\begin{array}{c}\text { Control } \\
\text { mean }(S D)\end{array}$ & $\mathrm{F}$ & $\mathrm{p}$ \\
\hline FHQ Total & $19.9(6.1)$ & $15.2(3.9)$ & $F(1,20)=5.614$ & 0.025 \\
HHIA & $32.5(31.33)$ & $6.75(12.8)$ & $F(1,27)=4.903$ & 0.037 \\
NSI Total & $33.9(21.3)$ & $14.1(12.4)$ & $F(1,27)=8.771$ & 0.006 \\
\hline
\end{tabular}

Behavioral

measures

\begin{tabular}{lccll}
\hline AzBio Quiet & $99(1.4)$ & $99.5(.007)$ & $F(1,27)=1.690$ & 0.205 \\
AzBio +5 dB & $94(.05)$ & $96.6(.02)$ & $F(1,27)=2.612$ & 0.118 \\
$\quad$ SNR & & & & \\
AzBio 0 dB & $65(11.5)$ & $65.4(10.5)$ & $F(1,27)=0.012$ & 0.913 \\
SNR & & & & \\
CNC Quiet & $99.8(.005)$ & $99.9(.004)$ & $F(1,27)=0.167$ & 0.686 \\
CNC +5 dB & $86.5(6.9)$ & $89.6(3)$ & $F(1,27)=2.321$ & 0.272 \\
SNR & & & & \\
DDT & $94.6(5.3)$ & $97.5(2.2)$ & $F(1,22)=2.138$ & 0.158 \\
SSW & $6.3(5.9)$ & $2.5(1.9)$ & $F(1,22)=3.070$ & 0.094 \\
CWT - right & $93.7(6.3)$ & $99(1.7)$ & $F(1,22)=3.998$ & 0.06 \\
CWT - left & $93.3(4.0)$ & $98(1.3)$ & $F(1,22)=5.901$ & 0.025 \\
\hline
\end{tabular}

FHQ, Functional Hearing Questionnaire; HHIA, Hearing Handicap Inventory for Adults; NSI, Neurobehavioral Symptom Inventory; SNR, signal-to-noise ratios; CNC, Consonant-Nucleus-Consonant; DDT, Dichotic Digits Test; SSW, Staggered Spondaic Words; CWT, Compressed Word Test. 


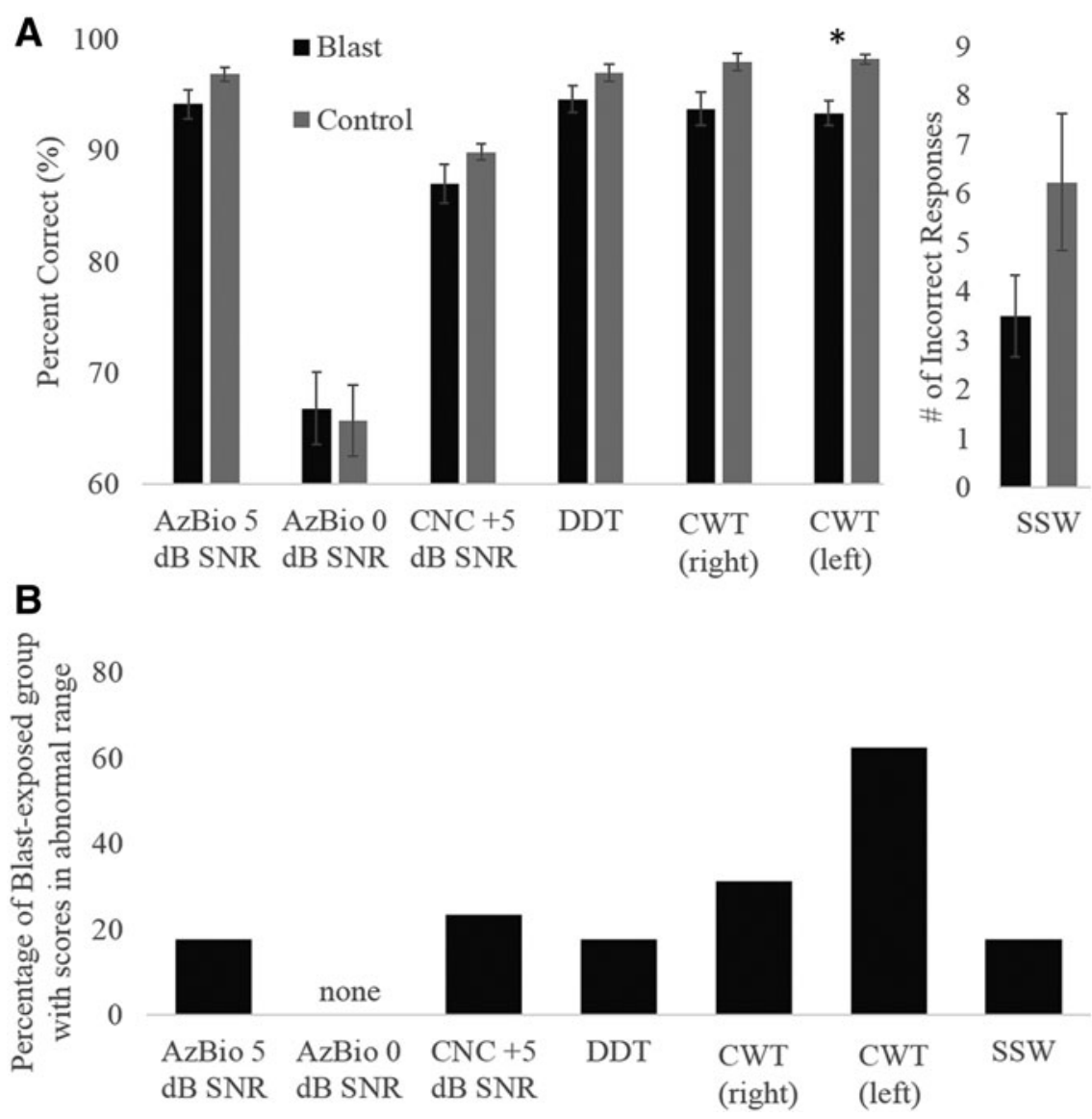

FIG. 2. (A) Average performance of blast-exposed (black) and control (gray) subjects on behavioral tests of auditory perception. *Indicates significant group difference at the level of $p<0.05$. Error bars indicate \pm 1 SEM. (B) The percentage of participants in the blast-exposed group with abnormal scores on each of the behavioral auditory perceptual tests. Abnormal performance was defined as $>2$ standard deviations below the mean performance of control participants.

upon the performance criterion of \pm 2 standard deviations from the mean performance of the control group, $60 \%$ of the blast-exposed group scored in the abnormal range on the left-ear presentations of the CWT, whereas $33 \%$ scored in the abnormal range in response to right-ear presentations of the CWT (Fig. 2B).

\section{$P P I$ and habituation of the ASR}

Three control and six blast-exposed participants, all with a diagnosis of PTSD, opted not to complete the ASR protocol. Average group effects of PPI and habituation to the startle stimulus for both groups are shown in Figure 3. No significant group differences were found for the magnitude of the baseline ASR $\left(F_{(1,18)}=0.664\right.$; $p=0.426)$ or PPI of the ASR $\left(F_{(1,18)}=0.099 ; p=0.757\right)$; however, members of the blast-exposed group exhibited significantly less habituation to repetitions of the acoustic startle stimulus than did the control group $\left(F_{(1,18)}=14.593 ; p=0.001\right)$. Specifically, the ASR magnitude of the control group diminished by $69.5 \%$, compared with the blast-exposed group, which exhibited a reduction of $39 \%$.

\section{Subcortical and cortical sensory gating}

Analysis of AERP responses to the dual-click paradigm revealed significantly reduced sensory gating in the $\mathrm{P} 2$ peak response of the blast-exposed participant group compared with the control group
(Table 2). This effect was driven by significantly larger $\mathrm{P} 2$ peaks in response to the test stimulus among blast-exposed participants compared with control participants, whereas P2 amplitudes in response to the conditioning stimulus were similar between the two groups. This pattern can be seen in Figure 4, which depicts representative responses of a control (solid black line) and a blast-exposed (broken blue line) participant in response to the AERP sensory gating test. No significant group differences were found in P1 or N1 amplitude in response to the conditioning stimulus, test stimulus, or overall amount of sensory gating for these peaks (Table 2).

\section{Correlations}

To evaluate the relationship between neurophysiology and behavior, correlations were assessed among all measures of sensory gating (PPI, ASR habituation, and $\Delta \mathrm{P} 1, \Delta \mathrm{N} 1$, and $\Delta \mathrm{P} 2$ ) and behavioral measures of degraded and competing speech (AzBio in both noise conditions, CNC in $+5 \mathrm{~dB}$ SNR, CWT, DDT, and SSW). Table 3 presents the $\mathrm{T}_{\mathrm{b}}$ correlation coefficients as well as $p$ values for these comparisons. A Benjamini-Hochberg correction with a false discovery rate of $10 \%$ applied to all 35 test comparisons revealed that values of $p<0.011$ indicated statistically significant correlations. According to this analysis, $\Delta \mathrm{P} 1, \Delta \mathrm{P} 2$, and ASR habituation were each significantly correlated with behavioral measures. The strongest associations were between ASR habituation and performance on the CWT presented to the left ear (Fig. 5A) and 


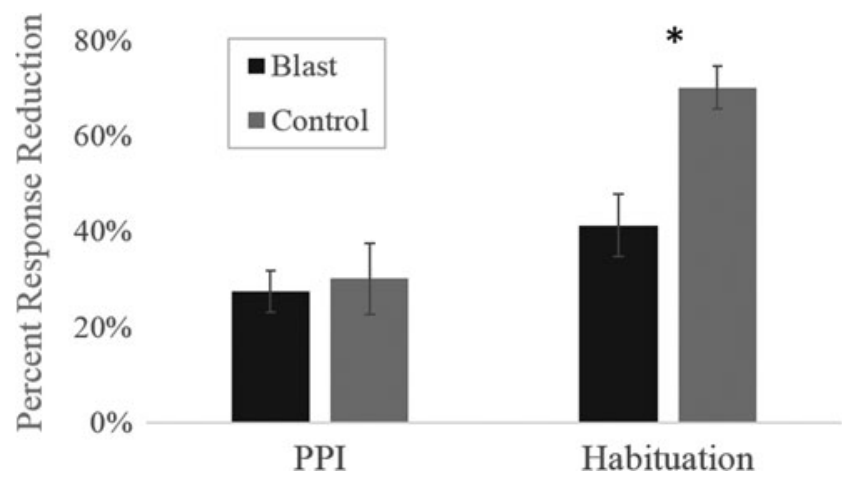

FIG. 3. Average percent change in the magnitude of the startle response in blast-exposed (black) and control (gray) participants in response to pre-pulse inhibition (PPI) trials and after habituation to the startle stimulus. *Indicates significant group difference at the level of $p<0.05$. Error bars indicate \pm 1 SEM.

right ear, followed by the association between $\Delta \mathrm{P} 2$ and CWT presented to the right ear (Fig. 5B). In each case, as predicted, the direction of the correlation indicates that poorer sensory gating is associated with poorer performance on the CWT.

The contribution of demographic variables such as age, TBI diagnosis, PTSD diagnosis, neurobehavioral symptoms, number of brain injuries, time since injury, and years of military service to our sensory gating variables was also assessed using correlations. Poorer ASR habituation was significantly correlated with diagnoses of PTSD $\left(\mathrm{T}_{\mathrm{b}}=-0.522 ; p=0.007\right)$ and TBI $\left(\mathrm{T}_{\mathrm{b}}=-0.433 ; p=0.024\right)$, a greater number of total number of brain injuries $\left(\mathrm{T}_{\mathrm{b}}=-0.435\right.$; $p=0.012)$, and with more severe neurobehavioral symptoms $\left(\mathrm{T}_{\mathrm{b}}=\right.$ -0.368; $p=0.025$ ). Poorer $\mathrm{P} 2$ sensory gating (e.g., smaller $\Delta \mathrm{P} 2$ values) was significantly correlated with diagnoses of $\mathrm{TBI}\left(\mathrm{T}_{\mathrm{b}}=\right.$ -0.445; $p=0.005)$ and PTSD $\left(\mathrm{T}_{\mathrm{b}}=-0.405 ; p=0.010\right)$, and with total number of brain injuries $\left(\mathrm{T}_{\mathrm{b}}=-0.357 ; p=0.011\right)$. No demographic variables were significantly correlated with $\Delta \mathrm{P} 1, \Delta \mathrm{N} 1$, or PPI.

\section{Factors predictive of sensory gating and auditory behavioral performance}

Because several significant correlations were identified during our initial assessment of the relationship between sensory gating indices and demographic variables, we next performed stepwise linear regression analyses to parse out which factors are most predictive of impaired sensory gating. The effects of TBI diagnosis, PTSD diagnosis, years of military service, and self-report auditory and neurobehavioral symptoms were examined on $\triangle \mathrm{P} 2$ and on ASR habituation. The probability-of- $F$-to-enter criterion was $\leq 0.05$, and the probability-of- $F$-to-remove criterion was set to $\geq 0.100$ for both analyses. The model predicting habituation to the startle stimulus contained only one predictive variable: diagnosis of PTSD. The model met criteria for statistical significance $\left(F_{(1,15)}=6.796\right.$; $p=0.021$, with PTSD diagnosis accounting for $\sim 30 \%$ of the variance of habituation to the startle stimulus $\left(R^{2}=0.327\right.$; adjusted $\left.R^{2}=0.279\right)$. The model predicting sensory gating indexed by $\Delta \mathrm{P} 2$ also revealed a single significant predictive variable: diagnosis of TBI. Again, the model met criteria for statistical significance $\left(F_{(1,22)}=13.479 ; p=0.001\right)$, with TBI diagnosis accounting for $>35 \%$ of the variance of $\Delta \mathrm{P} 2\left(R^{2}=0.380\right.$; adjusted $\left.R^{2}=0.352\right)$.

In addition to investigating the effects of blast exposure on sensory gating, a second question of the current study was whether sensory gating affected performance on auditory tests involving competing or degraded speech. Both $\triangle \mathrm{P} 2$ and ASR habituation were significantly correlated with the CWT (Table 3; Fig. 5A and B). However, significant correlations with CWT performance were also found for TBI and PTSD diagnoses. To investigate the relative influence of each of these factors on CWT performance, an additional stepwise multiple regression analysis was completed using CWT performance in the right ear as the dependent variable and $\triangle \mathrm{P} 2$, ASR habituation, PTSD diagnosis, and TBI diagnosis as independent variables. The probability-of- $F$-to-enter criterion was $\leq 0.05$, and the probability-of- $F$-to-remove criterion was set to $\geq 0.100$. The resulting predictive model met criteria for statistical significance $\left(F_{(2,11)}=8.562 ; p=0.006\right)$ and accounted for $\sim 60 \%$ of the variance in CWT performance $\left(R^{2}=0.609\right.$; adjusted $R^{2}=0.538$ ). ASR habituation alone accounted for $42.7 \%$ of the variance in CWT performance, and the addition of $\Delta \mathrm{P} 2$ accounted for an additional $18.1 \%$. Comparison of the predictive model's performance compared with observed performance values on the CWT are shown in Figure 6.

\section{Discussion}

The present study investigated two primary questions. The first was whether or not exposure to high-intensity blast waves impairs

Table 2. Group Averages, Standard Deviations, and Statistical Group Comparison of Responses to Conditioning and Test Stimuli Presented in the Paired-Click Sensory Gating Paradigm

\begin{tabular}{|c|c|c|c|}
\hline & $\begin{array}{l}\text { Conditioning }(\mu V) \\
\text { mean }(S D)\end{array}$ & $\begin{array}{l}\text { Test }(\mu V) \\
\text { mean }(S D)\end{array}$ & $\begin{array}{c}\text { Percent change }(\%) \\
\text { mean }(S D)\end{array}$ \\
\hline \multicolumn{4}{|l|}{ P1 } \\
\hline Blast & $0.400(.36)$ & $0.187(.26)$ & $54.13(56.7)$ \\
\hline Control & $0.606(.30)$ & $0.262(.16)$ & $51.68(20.5)$ \\
\hline ANOVA: & $F(1,27)=2.713 ; p=0.111$ & $F(1,27)=0.808 ; p=0.368$ & $F(1,27)=0.022 ; p=0.884$ \\
\hline \multicolumn{4}{|l|}{ N1 } \\
\hline Blast & $-2.525(1.48)$ & $-1.546(.86)$ & $36.03(30.7)$ \\
\hline Control & $-2.775(2.06)$ & $-1.69(.98)$ & $30.88(29.6)$ \\
\hline ANOVA: & $F(1,27)=0.144 ; p=0.707$ & $F(1,27)=0.169 ; p=0.684$ & $F(1,27)=0.209 ; p=0.651$ \\
\hline \multicolumn{4}{|l|}{$\mathrm{P} 2$} \\
\hline Blast & $4.722(2.37)$ & $2.070(.78)$ & $51.87(16)$ \\
\hline Control & $4.213(1.25)$ & $1.456(.71)$ & $65.74(13.8)$ \\
\hline ANOVA: & $F(1,27)=0.487 ; p=0.491$ & $F(1,27)=4.783 ; p=0.038$ & $F(1,27)=6.085 ; p=0.020$ \\
\hline
\end{tabular}

Bolded values indicate significance at the level of $p<0.05$. 


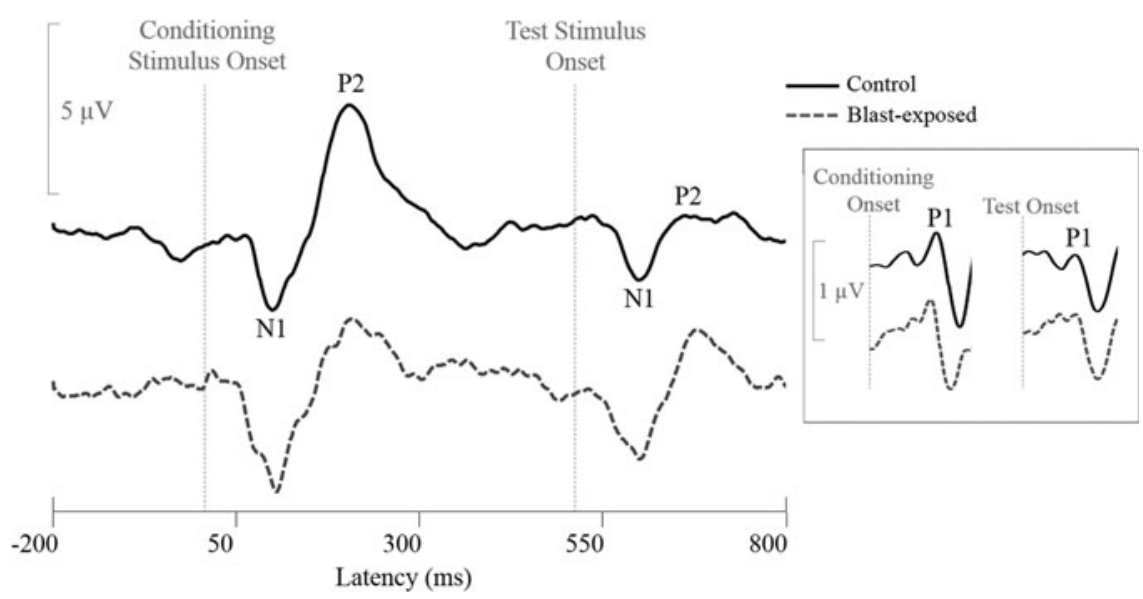

FIG. 4. Auditory evoked potentials (AERP) waveforms obtained in a representative control (solid line) and a representative blastexposed (broken line) participant in response to the paired-click sensory gating paradigm. N1 and P2 responses to both the conditioning and test stimuli are indicated on the control waveform. Inset to the right shows P1 responses, which were analyzed using different filter settings from those of the N1 and P2 peaks.

sensory gating. The second was whether or not impaired sensory gating was associated with auditory difficulties. Overall, the results of the present study indicate that blast exposure does increase the risk of sensory gating impairment, as revealed by the significant group differences in both habituation to the acoustic startle stimulus and cortical sensory gating indexed by the P2 peak of the AERP. Sensory gating measures were significantly associated with performance on auditory tasks including dichotic listening, perception of words in noise, and perception of rapid speech. Further, both ASR habituation and $\Delta \mathrm{P} 2$ were significant predictors of performance on a test of time-compressed speech. These two physiological indicators were better predictors of behavioral auditory performance than any other factors, including diagnoses of TBI, PTSD, age, time in the military, or self-reported measures of hearing abilities.

Currently, the mechanisms through which blast exposure impairs auditory processing are not well understood. The underlying hypothesis of the current study, that sensory gating abnormalities contribute to auditory performance deficits, is based upon the theory that sensory gating plays an important role in the preattentive filtering of sensory information for relevant content prior to the processing of this information by higher order cognitive regions. ${ }^{24,42}$ Thus, sensory gating normally helps to ensure that the cortex is not bombarded by extraneous information, and helps to focus higher order cognitive functions such as attention on the most relevant environmental input. ${ }^{43}$ Our data from both ASR habituation and cortical sensory gating generally support this hypothesis.

Although baseline ASR magnitude did not differ between groups, blast-exposed participants failed to habituate to repeated presentations of the startle stimulus, indicating continuing response to repeated, and what should become irrelevant, environmental input. Similarly, although we found no significant difference in the amplitude of response to the conditioning stimulus, $\mathrm{P} 2$ responses to the test stimulus (and resulting $\Delta \mathrm{P} 2$ ) in the blast-exposed group were significantly larger than responses in the control group, indicating an abnormally large response to redundant stimuli. These findings support the notion that redundant and irrelevant auditory information is often over-represented in the auditory system of veterans who have been exposed to high-intensity blasts.

Impaired sensory gating is likely to affect higher-order functions including speech perception in difficult listening conditions, possibly by diminishing the listener's capacity to attend to multiple acoustic streams simultaneously and apply linguistic analysis in real time. This interpretation is substantiated by factors such as the strong correlations between sensory gating measures and performance on difficult listening tasks (Table 3, Fig. 5), and by the

Table 3. Correlations between Measures of Sensory Gating and Behavioral Auditory Tests

\begin{tabular}{|c|c|c|c|c|c|c|c|}
\hline & $A z B i o+5 d B S N R$ & AzBio $0 \mathrm{~dB} S N R$ & $C N C+5 d B S N R$ & $D D T$ & $S S W$ & CWT Right ear & CWT Left ear \\
\hline PPI & $\tau \mathrm{b}=0.144$ & $\tau \mathrm{b}=-0.222$ & $\tau \mathrm{b}=-0.027$ & $\tau \mathrm{b}=-0.113$ & $\tau \mathrm{b}=-0.147$ & $\tau \mathrm{b}=0.135$ & $\tau \mathrm{b}=0.232$ \\
\hline & $p=0.392$ & $p=.173$ & $p=0.870$ & $p=0.554$ & $p=0.439$ & $p=0.572$ & $p=0.266$ \\
\hline Habituation & $\tau \mathrm{b}=0.199$ & $\tau \mathrm{b}=0.148$ & $\tau \mathrm{b}=0.211$ & $\tau \mathrm{b}=0.026$ & $\tau \mathrm{b}=-0.199$ & $\tau \mathbf{b}=\mathbf{0 . 5 7 7}$ & $\tau b=0.718$ \\
\hline & $p=0.236$ & $p=0.363$ & $p=0.202$ & $p=0.891$ & $p=0.295$ & $p=0.007$ & $p=0.001$ \\
\hline$\Delta \mathrm{P} 1$ & $\tau \mathrm{b}=0.041$ & $\tau \mathrm{b}=0.109$ & $\tau \mathrm{b}=0.058$ & $\tau b=0.408$ & $\tau \mathrm{b}=-0.281$ & $\tau \mathrm{b}=0.125$ & $\tau \mathrm{b}=0.052$ \\
\hline & $p=0.762$ & $p=0.409$ & $p=0.664$ & $p=0.007$ & $p=0.064$ & $p=0.455$ & $p=0.756$ \\
\hline$\Delta \mathrm{N} 1$ & $\begin{array}{l}\tau \mathrm{b}=-0.113 \\
p=0.405\end{array}$ & $\begin{array}{l}\tau \mathrm{b}=0.109 \\
p=0.409\end{array}$ & $\begin{array}{l}\tau b=-0.043 \\
p=0.784\end{array}$ & $\begin{array}{l}\tau \mathrm{b}=-0.195 \\
p=0.200\end{array}$ & $\begin{array}{l}\tau \mathrm{b}=0.030 \\
p=0.841\end{array}$ & $\begin{array}{l}\tau \mathrm{b}=-0.031 \\
p=0.852\end{array}$ & $\begin{array}{l}\tau \mathrm{b}=-0.021 \\
p=0.901\end{array}$ \\
\hline$\Delta \mathrm{P} 2$ & $\begin{array}{l}\tau \mathrm{b}=-0.044 \\
p=0.748\end{array}$ & $\begin{array}{l}\tau \mathrm{b}=-0.107 \\
p=0.419\end{array}$ & $\begin{array}{l}\tau \mathrm{b}=0.061 \\
p=0.650\end{array}$ & $\begin{array}{l}\tau \mathrm{b}=0.145 \\
p=0.340\end{array}$ & $\begin{array}{l}\tau \mathrm{b}=-0.163 \\
p=0.281\end{array}$ & $\begin{array}{l}\tau \mathrm{b}=\mathbf{0 . 4 4 8} \\
p=0.007\end{array}$ & $\begin{array}{l}\tau \mathrm{b}=0.275 \\
p=0.100\end{array}$ \\
\hline
\end{tabular}

Bolded values indicated significance at the level of $p<0.05$.

SNR, signal-to-noise ratio; CNC, Consonant-Nucleus-Consonant; DDT, Dichotic Digits Test; SSW, Staggered Spondaic Words; CWT, Compressed Word Test; PPI, pre-pulse inhibition. 

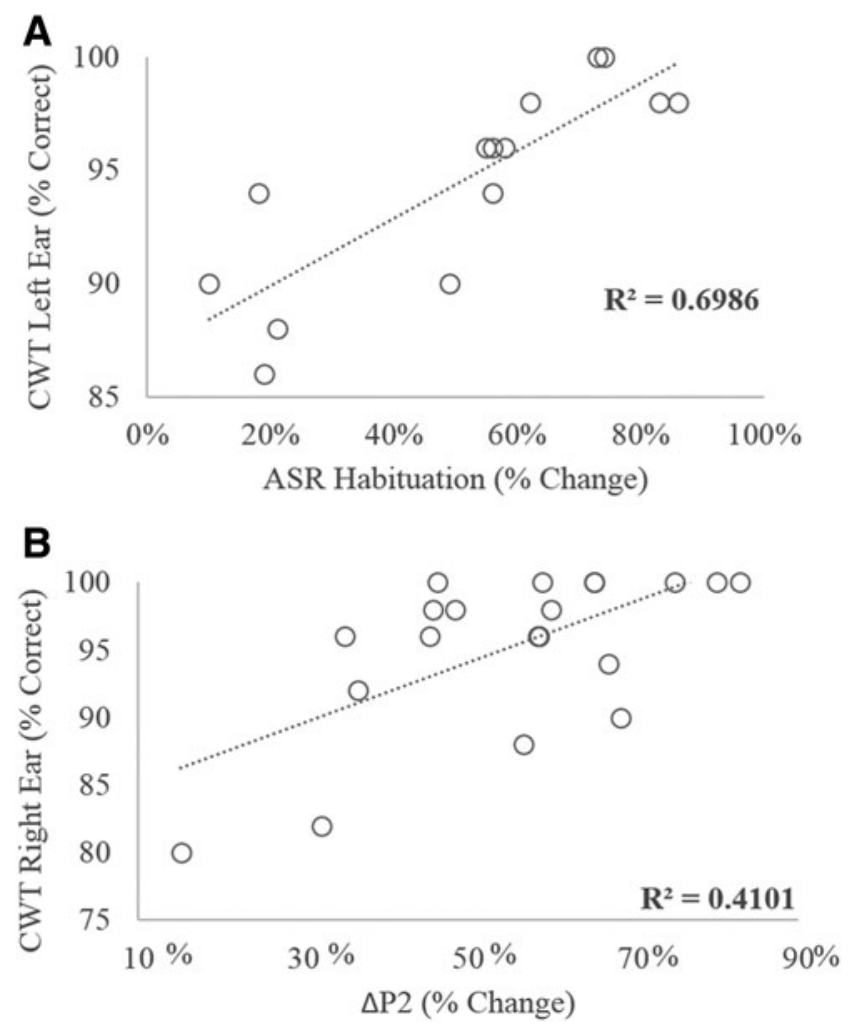

FIG. 5. Significant correlations were found between habituation to the acoustic startle reflex (ASR) stimulus and performance on the Compressed Word Test (CWT) presented to the left ear (panel A) and between P2 sensory gating and performance on the CWT presented to the right ear.

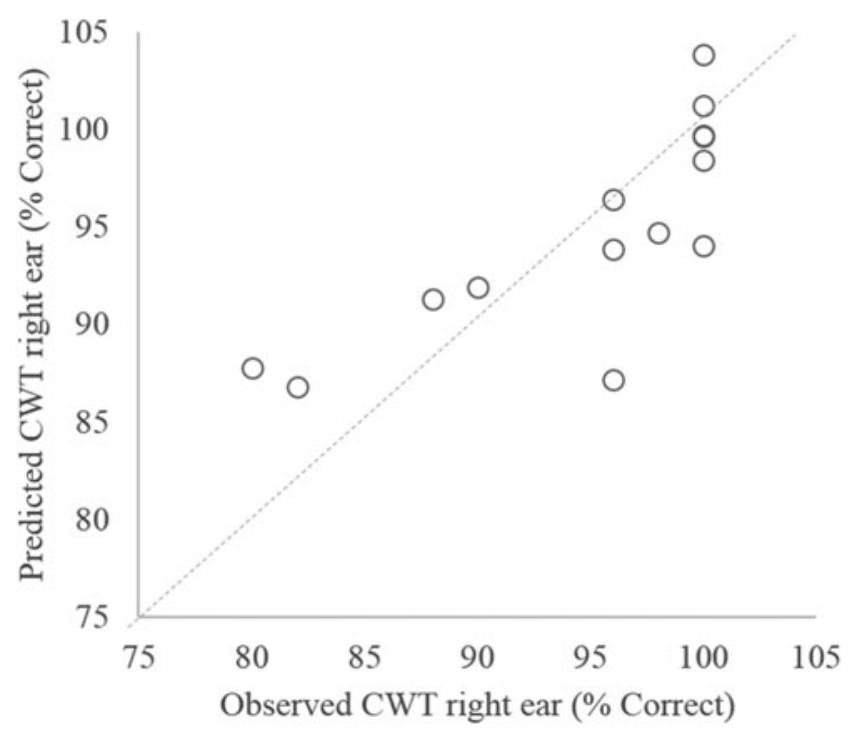

FIG. 6. Results of stepwise linear regression exploring the influence of traumatic brain injury (TBI) diagnosis, post-traumatic stress disorder (PTSD) diagnosis, and physiological measures of sensory gating on performance on the Compressed Word Test (CWT) presented to the right ear. Analysis revealed that only $\Delta \mathrm{P} 2$ and acoustic startle reflex (ASR) habituation were significant predictors of performance. results of other studies indicating that patients with persistent post-concussive symptoms often have mild cognitive impairment and increased response times. ${ }^{44-46}$ Additional physiological evidence comes from multiple studies indicating that the brains of patients with previous blast exposure and mTBI show less distinction between redundant and novel stimuli than neurologically normal brains when measured using AERP oddball stimulus paradigms. $^{18,21,47,48}$ Because sensory gating impairments typically affect more than one sensory modality, it is possible that poor sensory gating contributes to deficits often reported by TBI patients in other sensory domains such as vision and somatosensory stimulation. ${ }^{12,49-51}$

A particularly interesting outcome of the present study was the finding that poor habituation to acoustic startle stimuli was associated with a diagnosis of PTSD, whereas poor cortical sensory gating was associated with a diagnosis of TBI. The relationship among PTSD, TBI, and poor habituation may be explained by the theory of fear conditioning and associated fear-potentiated startle response. Recent work by Callahan and Storzbach ${ }^{52}$ demonstrated a significant relationship between PTSD-related intrusive experiences and noise sensitivity in a deployed veteran sample with blast exposure and mTBI. They found that those who had had traumarelated intrusive experiences maintained a heightened sensitivity to noise consistent with a chronic, maladaptive hyperarousal state. ${ }^{53,54}$ Persistent hyperarousal is associated with excessive autonomic pathway activation, ${ }^{55,56}$ which is in turn associated with increased startle reactivity, ${ }^{22,57,58}$ thus providing a direct autonomic nervous system connection between persistent PTSD symptoms and reduced ASR habituation. ${ }^{59}$

The relationship between reduced P2 sensory gating and TBI diagnosis is likely to be less direct than that between PTSD and poor ASR habituation, because the neural pathway underlying P2 responses is considerably more complex than that controlling the ASR. On the other hand, the complexity of neural underpinnings of $\mathrm{P} 2$ responses may be the critical factor linking TBI and P2 sensory gating. Neural damage in TBI is by nature diffuse, heterogenous, and complex. Although a hallmark of mTBI has been a lack of observable structural damage on standard clinical imaging protocols, more advanced imaging techniques as well as animal models have revealed the chronic presence of diffuse axonal injury (DAI) in areas including the temporal and frontal cortices, ${ }^{60}$ interhemispheric tracts including the corpus callosum, ${ }^{61-64}$ corticalsubcortical tracts, ${ }^{62,63}$ frontoparietal tracts, ${ }^{62}$ and cerebellum. ${ }^{61}$ Additional neurobiological effects of TBI include stunted dendritic outgrowths in GABAergic cortical neurons, ${ }^{65}$ mossy fiber sprouting in the hippocampus and increases in excitatory synapses, ${ }^{66}$ and excitatory input to cortical pyramidal neurons. ${ }^{67}$ In the chronic phase of recovery from mTBI, there is considerable evidence of hyperexcitability in sensory cortical areas ${ }^{65,68,69}$ largely driven by decreased activity of inhibitory neurotransmitters and the resulting imbalance of excitatory and inhibitory cortical networks. ${ }^{70-72}$ This pattern of cortical hyperexcitability is likely a consequence of maladaptive restructuring of cortical networks in response to widespread damage. ${ }^{68,69,73}$ AERP P2 response peaks are generated predominately by the primary auditory cortex, which depends on the integrity of the auditory pathway from the cochlea to the cortex, as well as the secondary auditory cortex, which receives input from the primary auditory cortex and from additional cortical and subcortical regions involved in the processing and integration of auditory stimuli. ${ }^{74,75}$ Therefore, the abnormally large $\mathrm{P} 2$ responses to redundant stimuli observed in our blast-exposed veterans, and the predictive power of TBI diagnosis on P2 sensory gating, are likely 
to represent the culmination of diffuse damage to cortical and subcortical neural pathways, and the resulting maladaptive hyperexcitability in the auditory cortex.

Other studies have shown changes in the P1 (also known as P50) amplitude in AERP testing of blast-exposed veterans. Work by Arciniegas and colleagues examined patients who had sustained non-blast-related TBIs at least 1 year prior to testing. ${ }^{21,76}$ Not only were TBI patients found to have reduced $\mathrm{P} 1$ sensory gating, but this condition was also found to be associated with reduced hippocampal volume. ${ }^{77}$ Interestingly, the authors reported that P1 response among TBI patients to the conditioning stimulus was significantly smaller than in control participants, whereas the response to the test stimulus was significantly larger. In contrast, we found no significant group differences among P1, N1, or P2 amplitudes in response to the conditioning stimulus (Table 2); only P2 response to the test stimulus was found to be significantly larger in blast-exposed veterans. Discrepancies among studies may be partially the result of methodological differences. For example, the current study employed longer duration stimuli $(10 \mathrm{~ms}$ vs. $1 \mathrm{~ms}$ clicks) presented at a higher intensity, and results were based on responses to an average of 178 trials (minimum of 146), whereas previous studies were based on only 48 stimulus trials with no mention of control for artifacts or eye blinks. Therefore, the AERP results of the current study are undoubtedly less affected by trial-totrial response variability than those of earlier studies. In addition, differences among participant populations may also explain discrepant study results. The previous studies included individuals with mild, moderate, and severe TBI who also had complaints of persistent cognitive impairments, whereas the current study examined only blast-exposed veterans with a diagnosis of mTBI or who reported symptoms following blast exposure that were consistent with mTBI. Therefore, severity of injury may be a significant factor affecting sensory gating at the thalamocortical levels indexed by the P1 response, whereas sensory gating deficits in those with less severe injuries are more likely to be revealed by early cortical responses. $\mathrm{P} 2$ responses have been posited to reflect filtering mechanisms involved in the allocation of attention and working memory ${ }^{27,78}$ whereas $\mathrm{P} 1$ responses are believed to reflect the fidelity of stimulus encoding of information from the brainstem to the auditory cortex. ${ }^{79,80}$ Therefore, deficits in P1 and P2 sensory gating likely reflect different filtering mechanisms with potentially different functional outcomes.

\section{Limitations}

Although our study included the use of several complementary methods, including both subjective and objective methods, to ascertain the effect of blast exposure on different levels of auditory function, some limitations remain. First, the sample size was fairly small, and although it was adequately powered to detect significant group differences, it could be susceptible to random sampling effects and sampling bias. For example, the population was primarily self-referred, which inherently carries potential selection bias, although this was mitigated by the use of a self-referred control comparison group. Second, diagnosis of TBI was largely based on self-report and medical record confirmation. Participants were not required to have a medical diagnosis of TBI for study participation both because our previous work has suggested that blast exposure can yield chronic auditory difficulties without a TBI diagnosis, and because many service members report that they are reluctant to report brain injuries to their superiors during active duty in the absence of visible injuries. However, this leaves open the possi- bility that participants were not accurate in their recollections of symptoms following blast exposure. Lastly, although the findings of associations among TBI, PTSD, and sensory gating are exciting, there was a significant overlap between TBI and PTSD in the current sample. Therefore, these findings should be replicated in future studies that better isolate TBI and PTSD populations.

\section{Acknowledgments}

The authors express their sincere appreciation and gratitude for the participation of all subjects, and thank the staff at the VA Portland Health Care System and the National Center for Rehabilitative Auditory Research and Drs. Mary Beth Duncan and Curtis Billings for support with establishing protocols and initial data analysis. This material is the result of work supported with resources and the use of facilities at the VA Portland Health Care System, VA Office of Academic Affiliations (OAA) Advanced Research Fellowship in Polytrauma/TBI Rehabilitation, and VA Career Development Award IK1RX001820 to M.A.P.; VA Rehabilitation Research and Development (RR\&D) Merit Award \#C7755I to F.J.G; National Institutes of Health (N.I.H.) T32 AT 002688 to J.E.E.; and VA Career Development Award \#IK2 BX002712, and the Portland VA Research Foundation to M.M.L. The contents do not represent the views of the United States Department of Veterans Affairs or the United States Government.

\section{Author Disclosure Statement}

No competing financial interests exist.

\section{References}

1. Defense and Veterans Brain Injury Center (2018). DoD Worldwide Numbers for TBI. http://dvbic.dcoe.mil/dod-worldwide-numbers-tbi (last accessed January 22, 2018).

2. Greer, N., Sayer, N., Kramer, M., Koeller, E., and Velasquez, T. (2016). Prevalence and Epidemiology of Combat Blast Injuries from the Military Cohort 2001-2014. Department of Veterans Affairs: Washington, DC.

3. Terrio, H., Brenner, L.A., Ivins, B.J., Cho, J.M., Helmick, K., Schwab, K., Scally, K., Bretthauer, R., and Warden, D. (2009). Traumatic brain injury screening: preliminary findings in a US Army Brigade Combat Team. J. Head Trauma Rehabil. 24, 14-23.

4. Lew, H.L., Weihing, J., Myers, P.J., Pogoda, T.K., and Goodrich, G.L. (2010). Dual sensory impairment (DSI) in traumatic brain injury (TBI)-An emerging interdisciplinary challenge. NeuroRehabilitation 26, 213-222.

5. Saunders, G.H., Frederick, M.T., Arnold, M., Silverman, S., Chisolm, T.H., and Myers, P.J. (2015). Auditory difficulties in blast-exposed Veterans with clinically normal hearing. J. Rehabil. Res. Dev. 52, 343.

6. Gallun, F.J., Lewis, M.S., Folmer, R.L., Hutter, M., Papesh, M.A., Belding, H., and Leek, M.R. (2016). Chronic effects of exposure to high-intensity blasts: Results of tests of central auditory processing. J. Rehabil. Res. Dev. 53, 705.

7. Trudeau, D.L., Anderson, J., Hansen, L.M., Shagalov, D.N., Schmoller, J., Nugent, S., and Barton, S. (1998). Findings of mild traumatic brain injury in combat veterans with PTSD and a history of blast concussion. J. Neuropsychiatry Clin. Neurosci. 10, 308-313.

8. Schneiderman, A.I., Braver, E.R., and Kang, H.K. (2008). Understanding sequelae of injury mechanisms and mild traumatic brain injury incurred during the conflicts in Iraq and Afghanistan: persistent postconcussive symptoms and posttraumatic stress disorder. Am. J. Epidemiol. 167, 1446-1452.

9. Lew, H.L., and Guillory, S.B. (2007). Auditory dysfunction in traumatic brain injury. J. Rehabil. Res. Dev. 44, 921.

10. Bergemalm, P.-O., and Lyxell, B. (2005). Appearances are deceptive? Long-term cognitive and central auditory sequelae from closed head injury. Int. J. Audiol. 44, 39-49. 
11. Oleksiak, M., St Andre, J.R., and Steiner, M. (2012). Audiological issues and hearing loss among Veterans with mild traumatic brain injury. J. Rehabil. Res. Dev. 49, 995.

12. Callahan, M.L., Binder, L.M., O'Neil, M.E., Zaccari, B., Roost, M.S., Golshan, S., Huckans, M., Fann, J.R., and Storzbach, D. (2018). Sensory sensitivity in operation enduring freedom/operation Iraqi freedom veterans with and without blast exposure and mild traumatic brain injury. Appl. Neuropsychol. Adult 25, 126-136.

13. Fausti, S.A., Wilmington, D.J., Gallun, F.J., Myers, P.J., and Henry, J.A. (2009). Auditory and vestibular dysfunction associated with blast-related traumatic brain injury. J. Rehabil. Res. Dev. 46, 797810.

14. Myers, P.J., Wilmington, D.J., Gallun, F.J., Henry, J.A., and Fausti, S.A. (2009). Hearing impairment and traumatic brain injury among soldiers: special considerations for the audiologist in: Seminars in Hearing. Thieme Medical Publishers: Stuttgart, Germany, pps. 5-27.

15. Gallun, F.J., Papesh, M.A., and Lewis, M.S. (2017). Hearing complaints among veterans following traumatic brain injury. Brain Inj. 31, $1183-1187$.

16. Schultz, B.A., Cifu, D.X., McNamee, S., Nichols, M., and Carne, W. (2011). Assessment and treatment of common persistent sequelae following blast induced mild traumatic brain injury. NeuroRehabilitation 28, 309-320.

17. Hoover, E.C., Souza, P.E., and Gallun, F.J. (2015). Competing views on abnormal auditory results after mild traumatic brain injury. Perspect. Hear. Hear. Disord. Res. Diagn. 19, 12-21.

18. Gallun, F.J., Diedesch, A.C., Kubli, L.R., Walden, T.C., Folmer, R.L., Lewis, M.S., McDermott, D.J., Fausti, S.A., and Leek, M.R. (2012). Performance on tests of central auditory processing by individuals exposed to high-intensity blasts. J. Rehabil. Res. Dev. 49, 1005.

19. Cromwell, H.C., Mears, R.P., Wan, L., and Boutros, N.N. (2008). Sensory gating: a translational effort from basic to clinical science. Clin. EEG Neurosci. 39, 69-72.

20. Freedman, R., Adler, L.E., Gerhardt, G.A., Waldo, M., Baker, N. Rose, G.M., Drebing, C., Nagamoto, H., Bickford-Wimer, P., and Franks, R. (1987). Neurobiological studies of sensory gating in schizophrenia. Schizophr. Bull. 13, 669.

21. Arciniegas, D., Olincy, A., Topkoff, J., McRae, K., Cawthra, E., Filley, C.M., Reite, M., and Adler, L.E. (2000). Impaired auditory gating and P50 nonsuppression following traumatic brain injury. J. Neuropsychiatry Clin. Neurosci. 12, 77-85.

22. Braff, D.L., Grillon, C., and Geyer, M.A. (1992). Gating and habituation of the startle reflex in schizophrenic patients. Arch. Gen. Psychiatry $49,206-215$.

23. Geyer, M.A., and Braff, D.L. (1987). Startle habituation and sensorimotor gating in schizophrenia and related animal models. Schizophr. Bull. 13, 643 .

24. Braff, D.L., Geyer, M.A., and Swerdlow, N.R. (2001). Human studies of prepulse inhibition of startle: normal subjects, patient groups, and pharmacological studies. Psychopharmacology 156, 234-258.

25. Adler, L.E., Pachtman, E., Franks, R., Pecevich, M., Waldo, M., and Freedman, R. (1982). Neurophysiological evidence for a defect in neuronal mechanisms involved in sensory gating in schizophrenia. Biol. Psychiatry 17, 639-654.

26. Grunwald, T., Boutros, N.N., Pezer, N., von Oertzen, J., Fernández, G., Schaller, C., and Elger, C.E. (2003). Neuronal substrates of sensory gating within the human brain. Biol. Psychiatry 53, 511-519.

27. Lijffijt, M., Lane, S.D., Meier, S.L., Boutros, N.N., Burroughs, S., Steinberg, J.L., Gerard Moeller, F., and Swann, A.C. (2009). P50, N100, and P200 sensory gating: relationships with behavioral inhibition, attention, and working memory. Psychophysiology 46, 10591068.

28. Hoover, E.C., Souza, P.E., and Gallun, F.J. (2017). Auditory and cognitive factors associated with speech-in-noise complaints following mild traumatic brain injury. J. Am. Acad. Audiol. 28, 325-339.

29. Newman, C.W., Weinstein, B.E., Jacobson, G.P., and Hug, G.A. (1990). The Hearing Handicap Inventory for Adults: psychometric adequacy and audiometric correlates. Ear Hear. 11, 430-433.

30. Cicerone, K.D., and Kalmar, K. (1995). Persistent postconcussion syndrome: the structure of subjective complaints after mild traumatic brain injury. J. Head Trauma Rehabil. 10, 1-17.

31. Luxford, W.M. (2001). Minimum speech test battery for postlingually deafened adult cochlear implant patients. Otolaryngol. Head Neck Surg. 124, 125-126.
32. Spahr, A.J., Dorman, M.F., Litvak, L.M., Van Wie, S., Gifford, R.H., Loizou, P.C., Loiselle, L.M., Oakes, T., and Cook, S. (2012). Development and validation of the AzBio sentence lists. Ear Hear. 33, 112.

33. Peterson, G.E., and Lehiste, I. (1962). Revised CNC lists for auditory tests. J. Speech Hear. Disord. 27, 62-70.

34. Musiek, F.E. (1983). Assessment of central auditory dysfunction: the dichotic digit test revisited. Ear Hear. 4, 79-83.

35. Katz, J. (1962). The use of staggered spondaic words for assessing the integrity of the central auditory nervous-system. J. Aud. Res. 2, 327-337.

36. Wilson, R.H., Preece, J., Salamon, D., Sperry, J.L., and Bornstein, S.P. (1994). Effects of time compression and time compression plus reverberation on the intelligibility of Northwestern University Auditory Test No. 6. J. Am. Acad. Audiol. 5, 269-269.

37. Ghisolfi, E.S., Schuch, A., Strimitzer, I.M., Luersen, G., Martins, F.F., Ramos, F.L., Becker, J., and Lara, D.R. (2006). Caffeine modulates P50 auditory sensory gating in healthy subjects. Eur. Neuropsychopharmacol. 16, 204-210.

38. Knott, V., de la Salle, S., Smith, D., Phillipe, T., Dort, H., Choueiry, J., and Impey, D. (2013). Baseline dependency of nicotine's sensory gating actions: similarities and differences in low, medium and high P50 suppressors. J. Psychopharmacol. 27, 790-800.

39. Jerger, K., Biggins, C., and Fein, G. (1992). P50 suppression is not affected by attentional manipulations. Biol. psychiatry 31, 365-377.

40. Newson, R. (2001). Parameters behind "nonparametric" statistics: Kendall's tau, Somers' D and median differences. Strata J. 1, 1-20.

41. Croux, C., and Dehon, C. (2010). Influence functions of the Spearman and Kendall correlation measures. Stat. Methods Appl. 19, 497-515.

42. Gjini, K., Arfken, C., and Boutros, N.N. (2010). Relationships between sensory "gating out" and sensory "gating in" of auditory evoked potentials in schizophrenia: a pilot study. Schizophr. Res. 121, 139-145.

43. Patterson, J.V., Hetrick, W.P., Boutros, N.N., Jin, Y., Sandman, C., Stern, H., Potkin, S., and Bunney, W.E. (2008). P50 sensory gating ratios in schizophrenics and controls: a review and data analysis. Psychiatry Res. 158, 226-247.

44. Niogi, S., Mukherjee, P., Ghajar, J., Johnson, C., Kolster, R., Sarkar, R., Lee, H., Meeker, M., Zimmerman, R., and Manley, G. (2008). Extent of microstructural white matter injury in postconcussive syndrome correlates with impaired cognitive reaction time: a 3T diffusion tensor imaging study of mild traumatic brain injury. AJNR Am. J. Neuroradiol. 29, 967-973.

45. Kraus, M.F., Susmaras, T., Caughlin, B.P., Walker, C.J., Sweeney, J.A., and Little, D.M. (2007). White matter integrity and cognition in chronic traumatic brain injury: a diffusion tensor imaging study. Brain $130,2508-2519$.

46. McAllister, T.W., Sparling, M.B., Flashman, L.A., Guerin, S.J., Mamourian, A.C., and Saykin, A.J. (2001). Differential working memory load effects after mild traumatic brain injury. Neuroimage $14,1004-1012$

47. Folmer, R.L., Billings, C.J., Diedesch-Rouse, A.C., Gallun, F.J., and Lew, H.L. (2011). Electrophysiological assessments of cognition and sensory processing in TBI: applications for diagnosis, prognosis and rehabilitation. Int. J. Psychophysiol. 82, 4-15.

48. Kisley, M.A., Noecker, T.L., and Guinther, P.M. (2004). Comparison of sensory gating to mismatch negativity and self-reported perceptual phenomena in healthy adults. Psychophysiology 41, 604-612.

49. Lew, H.L., Garvert, D.W., Pei-Te Hsu, M., Devine, J.M., and White, D.K. (2009). Auditory and visual impairments in patients with blastrelated traumatic brain injury: Effect of dual sensory impairment on Functional Independence Measure. J. Rehabil. Res. Dev. 46, 819.

50. Lew, H.L., Pogoda, T.K., Baker, E., Stolzmann, K.L., Meterko, M., Cifu, D.X., Amara, J., and Hendricks, A.M. (2011). Prevalence of dual sensory impairment and its association with traumatic brain injury and blast exposure in OEF/OIF veterans. J. Head Trauma Rehabil. 26, 489-496.

51. Lew, H.L., Tun, C., and Cifu, D.X. (2009). Prevalence of chronic pain, posttraumatic stress disorder, and persistent postconcussive symptoms in OIF/OEF veterans: polytrauma clinical triad. J. Rehabil. Res. Dev. $46,697$.

52. Callahan, M.L., and Storzbach, D. (2018). Sensory sensitivity and posttraumatic stress disorder in blast exposed veterans with mild traumatic brain injury. Appl. Neuropsychol. Adult 1-9.

53. Yehuda, R., Southwick, S.M., Giller, E.L., Ma, X., and Mason, J.W. (1992). Urinary catecholamine excretion and severity of PTSD 
symptoms in Vietnam combat veterans. J. Nerv. Ment. Dis. 180 321-325.

54. Van der Kolk, B.A. (2006). Clinical implications of neuroscience research in PTSD. Ann. N. Y. Acad. Sci. 1071, 277-293.

55. Cohen, H., Kaplan, Z., Matar, M.A., Loewenthal, U., Zohar, J., and Richter-Levin, G. (2007). Long-lasting behavioral effects of juvenile trauma in an animal model of PTSD associated with a failure of the autonomic nervous system to recover. Eur. Neuropsychopharmacol. 17, 464-477.

56. Streeter, C., Gerbarg, P., Saper, R., Ciraulo, D., and Brown, R. (2012). Effects of yoga on the autonomic nervous system, gammaaminobutyric-acid, and allostasis in epilepsy, depression, and posttraumatic stress disorder. Med. Hypotheses 78, 571-579.

57. Bradley, M.M., Lang, P.J., and Cuthbert, B.N. (1993). Emotion, novelty, and the startle reflex: habituation in humans. Behav. Neurosci. 107,970

58. Grillon, C., and Baas, J. (2003). A review of the modulation of the startle reflex by affective states and its application in psychiatry. Clin Neurophysiol. 114, 1557-1579.

59. Prins, A., Kaloupek, D.G., and Keane, T.M. (1995). Psychophysiological evidence for autonomic arousal and startle in traumatized adult populations. In M.J. Friedman, D.S. Charney, and A.Y. Deutch (eds.), Neurobiological and Clinical Consequences of Stress: From Normal Adaptation to Post-Traumatic Stress Disorder. Lippincott Williams \& Wilkins Publishers: Philadelphia, PA, pp. 291-314.

60. Niogi, S.N., and Mukherjee, P. (2010). Diffusion tensor imaging of mild traumatic brain injury. Journal Head Trauma Rehabil. 25, 241-255.

61. Koliatsos, V.E., Cernak, I., Xu, L., Song, Y., Savonenko, A., Crain, B.J., Eberhart, C.G., Frangakis, C.E., Melnikova, T., and Kim, H. (2011). A mouse model of blast injury to brain: initial pathological, neuropathological, and behavioral characterization. J. Neuropathol. Exp. Neurol. 70, 399-416.

62. Davenport, N.D., Lim, K.O., Armstrong, M.T., and Sponheim, S.R. (2012). Diffuse and spatially variable white matter disruptions are associated with blast-related mild traumatic brain injury. Neuroimage 59, 2017-2024.

63. Petrie, E.C., Cross, D.J., Yarnykh, V.L., Richards, T., Martin, N.M., Pagulayan, K., Hoff, D., Hart, K., Mayer, C., and Tarabochia, M. (2014). Neuroimaging, behavioral, and psychological sequelae of repetitive combined blast/impact mild traumatic brain injury in Iraq and Afghanistan war veterans. J. Neurotrauma 31, 425-436.

64. Wright, D.K., Trezise, J., Kamnaksh, A., Bekdash, R., Johnston, L.A., Ordidge, R., Semple, B.D., Gardner, A.J., Stanwell, P., and O'Brien, T.J. (2016). Behavioral, blood, and magnetic resonance imaging biomarkers of experimental mild traumatic brain injury. Sci. Rep. 6, 28713.

65. Carron, S.F., Alwis, D.S., and Rajan, R. (2016). Traumatic brain injury and neuronal functionality changes in sensory cortex. Front. Syst. Neurosci. 10, 47.

66. Hunt, R.F., Scheff, S.W., and Smith, B.N. (2011). Synaptic reorganization of inhibitory hilar interneuron circuitry after traumatic brain injury in mice. J. Neurosci. 31, 6880-6890.

67. Jin, X., Huguenard, J.R., and Prince, D.A. (2010). Reorganization of inhibitory synaptic circuits in rodent chronically injured epileptogenic neocortex. Cereb. Cortex 21, 1094-1104.

68. Alwis, D.S., Yan, E.B., Morganti-Kossmann, M.-C., and Rajan, R. (2012). Sensory cortex underpinnings of traumatic brain injury deficits. PLoS One 7, e52169.
69. Alwis, D.S., Johnstone, V., Yan, E., and Rajan, R. (2013). Diffuse traumatic brain injury and the sensory brain. Clin. Exp. Pharmacol. Physiol. 40, 473-483.

70. Buritica, E., Villamil, L., Guzmán, F., Escobar, M.I., Garcia-Cairasco, N., and Pimienta, H.J. (2009). Changes in calcium-binding protein expression in human cortical contusion tissue. J. Neurotrauma 26, 2145-2155.

71. Pavlov, I., Huusko, N., Drexel, M., Kirchmair, E., Sperk, G., Pitkänen, A., and Walker, M. (2011). Progressive loss of phasic, but not tonic, GABAA receptor-mediated inhibition in dentate granule cells in a model of post-traumatic epilepsy in rats. Neuroscience 194, 208219.

72. Yi, J.-H., and Hazell, A.S. (2006). Excitotoxic mechanisms and the role of astrocytic glutamate transporters in traumatic brain injury. Neurochem. Int. 48, 394-403.

73. Greer, J.E., Hånell, A., McGinn, M.J., and Povlishock, J.T. (2013). Mild traumatic brain injury in the mouse induces axotomy primarily within the axon initial segment. Acta Neuropathol. 126, 59-74.

74. Rauschecker, J.P., and Scott, S.K. (2009). Maps and streams in the auditory cortex: nonhuman primates illuminate human speech processing. Nat. Neurosci. 12, 718 .

75. Hall, D.A., Johnsrude, I.S., Haggard, M.P., Palmer, A.R., Akeroyd, M.A., and Summerfield, A.Q. (2002). Spectral and temporal processing in human auditory cortex. Cereb. Cortex 12, 140-149.

76. Arciniegas, M.D., Adler, M.L., Topkoff, J., Cawthra, R.E., Filley, M. Christopher M., and Reite, M.M. (1999). Subject Review: attention and memory dysfunction after traumatic brain injury: cholinergic mechanisms, sensory gating, and a hypothesis for further investigation. Brain Inj. 13, 1-13.

77. Arciniegas, D.B., Topkoff, J.L., Rojas, D.C., Sheeder, J., Teale, P., Young, D.A., Sandberg, E., Reite, M.L., and Adler, L.E. (2001). Reduced hippocampal volume in association with p50 nonsuppression following traumatic brain injury. J. Neuropsychiatry Clin. Neurosci. 13, 213-221.

78. Näätänen, R., and Picton, T. (1987). The N1 wave of the human electric and magnetic response to sound: a review and an analysis of the component structure. Psychophysiology 24, 375-425.

79. Boutros, N.N., Korzyuko, O., Oliwa, G., Feingold, A., Campbell, D. McClain-Furmanski, D., Struve, F., and Jansen, B.H. (2004). Morphological and latency abnormalities of the mid-latency auditory evoked responses in schizophrenia: a preliminary report. Schizophr. Res. 70, 303-313.

80. Wan, L., Friedman, B.H., Boutros, N.N., and Crawford, H.J. (2008) P50 sensory gating and attentional performance. Int. J. Psychophysiol. 67, 91-100.

Address correspondence to: Melissa A. Papesh, AuD, PhD

NCRAR

VA Portland Health Care System 3710 SW US Veterans Hospital Road Mailcode P5-NCRAR Portland, OR 97239

E-mail: Melissa.Papesh@va.gov 